This Section of Epidemiology and Psychiatric Sciences appears in each issue of the Journal and is dedicated to all forms of creative production born of an intimate and individual urge, often secretive, unbound from the conventional art system rules. Through short descriptions of the Outsider art work of prominent artists and new protagonists often hosted in community mental health services, this section intends to investigate the latest developments of the contemporary art scene, where the distances between the edge and the center are becoming more and more vague.

Carole Tansella, Section Editor

\title{
Albert Moser. Concept and procedure in American photography
}

\section{Tansella}

Department of Time, Space, Image, Society, University of Verona, Verona, Italy

Key words: Contemporary art, continuity, outsider art, social environment.

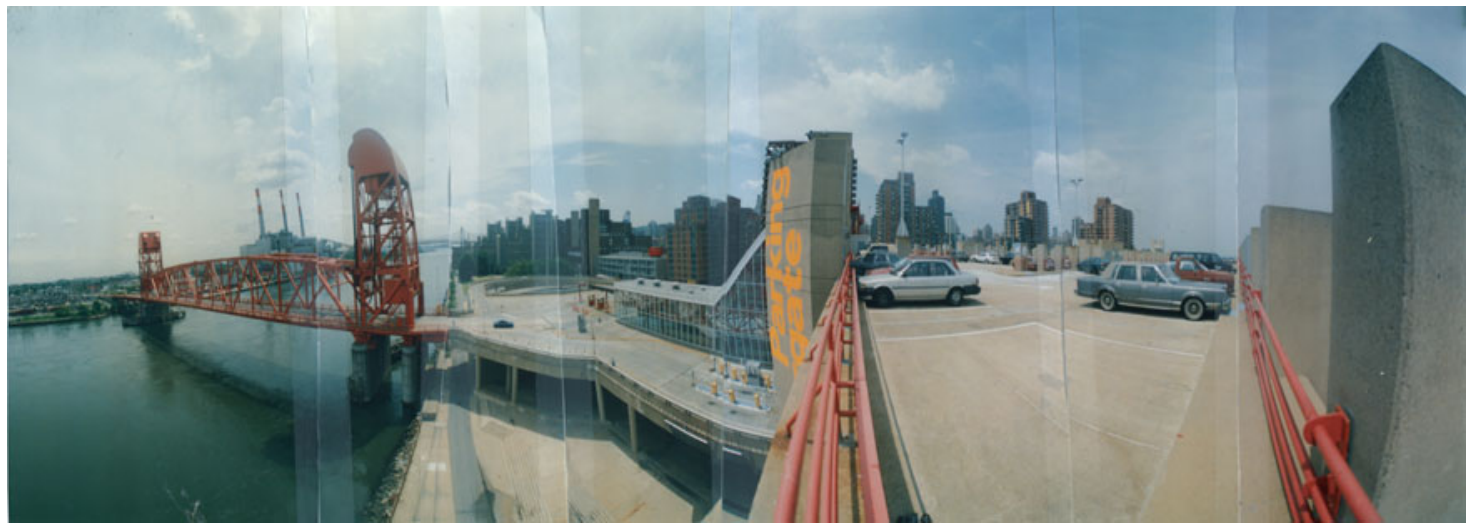

Fig. 1. A panoramic view of the 36th Ave Bridge, also Motorgate Parking Garage on Roosevelt Island, NY, 1995, photographs and masking or scotch-tape, description and signature on the back, $16.7 \times 52 \mathrm{~cm}$. Courtesy of Christian Berst Art Brut.

Here it is, this is America. This is the first thought that comes to mind when looking at the photographs of Albert Moser. These dry images, without frills, reveal to me how America really is. America as I dream her to be, America as I want her to be, America as I know her to be. The images are gratifying because they are not sublimated by any imperative. I see the

Address for correspondence: C. Tansella, Department of Time, Space, Image, Society, University of Verona, Verona, Italy.

(Email: carole.tansella@gmail.com) bare trees along sidewalks in winter, the deserted subway stations, the boundless sky over the ocean. I can hear the steady hum of cars at intersections revving and ready to go. I recognise the placid lack of prospects on a Sunday by the sea and the smell of copious pines in an autumn afternoon, fresh from the rain in a parking lot in West Dover, Vermont. I, who has never been to Vermont, am overcome with a feeling of Sehnsucht, and a longing to be in that parking lot, after the rain.

For over 35 years, Albert Moser has been photographing the urbia and the suburbia of a small part 


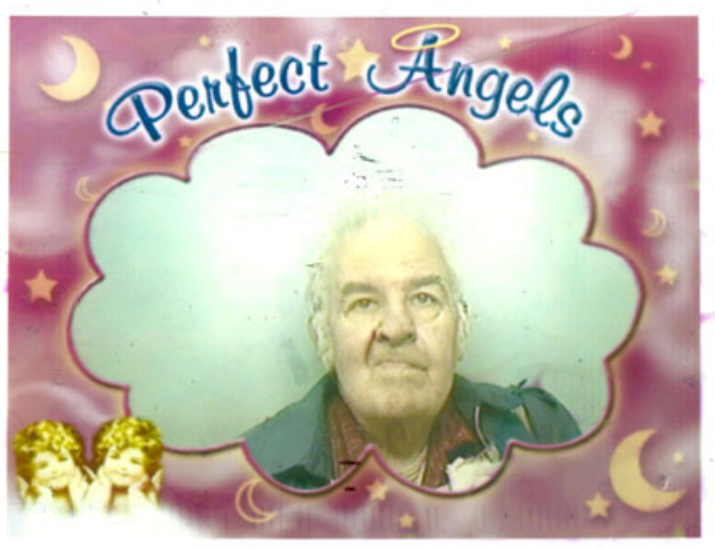

Fig. 2. Untitled, 1995, photographs and masking or scotchtape age, description and signature on the back, $16.8 \times 52 \mathrm{~cm}$. Courtesy of Christian Berst Art Brut.

of the north-eastern USA and immortalises it in a process attested to by time. When it comes to small cities like Trenton, New Jersey, and less often, in metropolitan areas, such as Atlantic City, Brooklyn or Philadelphia, Moser finds the best vantage point to capture the space around him. Then he shoots over 30 photographs, covering a $360^{\circ}$ visual angle. The end result is a panoramic image made up of a mosaic of cut and overlapped pictures held together with tape.

From 1970 until about 2005 Moser applied the same creative procedure and over time the series of panoramic photographs expanded to several hundred pieces. Like many outsider artists, Moser also concealed his work from external contact and kept to himself, tending to his work in secret. Like many photographers working during the 1970s in the USA, Moser also expressed the urge to categorise a vast and elusive land. The procedural aspect of his work, the geographically and technically-specific titles - A panoramic view of 8th Ave., N.Y.C., N.Y. (Penn Station in Middle foreground). Ansco Pix Panoramic Camera, Fujicolor Super HG2 100 color film - and the search for an anaesthetic reproduction of reality (Duchamp, 2005), place Moser's work in the specific artistic realm of conceptual art.

Albert Moser was born in 1928 in Trenton, New Jersey. From 1947 to 1948 he was deployed to Japan as part of the US occupying forces. After returning to the USA Moser took on a number of occasional and odd jobs. He worked for McGuire Air Force Base in Burlington, New Jersey, as well as sold candy in a department store and eventually worked alongside his father at his print shop. He enrolled at the School of Industrial Arts in Trenton to study photography in 1960. After receiving his diploma he joined the Trenton Camera Club (March Jones et al. 2012).
During the civil rights movement and cultural revolution of the 1960s, Moser began the series of panoramic, despite the fact that traditional artistic work was undergoing a radical rejection in favour of a new attitude imposed by the emerging conceptual art. The artistic process was held in higher regard than formal aesthetics and formal aspects of art work. Seriality and language became prevailing expressive practices of the time.

The photo exhibition New Topographics: Photographs of a Man-Altered Landscape of 1975 marks a turning point in traditional landscape photography (Jenkins, 1975). Bernd and Hilla Becher, Stephen Shore, Robert Adams and seven other photographers provide 'a vivid contribution to the developing portrait of the United States ... This new America was marked by repetition and isolation, a place increasingly dominated by quickly constructed buildings and a culture defined more by commerce than community, where people lived with a modicum of comfort but in an atmosphere of vacant alienation. The vision was so convincing that it instantly reshaped landscape photography with its celebration of directness, emotional removal and attractiveness to humanity's shaping of the land' (Foster-Rice \& Rohrbach, 2013).

In the continuous development of critical redefinition of the artistic process that outsider artists undergo - more so than other artists, Moser's work today has to be recognised as belonging specifically among the ranks of contemporary American landscape photography and categorised under conceptual art. This critical and verifiable method of classification of visual arts, serves to avoid running into epistemological impasse and create confusion between aesthetic theory and artistic poetry that keep the character and dignity of artistic work in check, as it happened to Moser in a recent catalogue where his work was understood as a result of his communication disorder (March Jones et al. 2012).

Albert Moser's work is conserved in France by the Collection Antoine de Galbert in Paris, and by the Collection abcd in Montreuil. His work can also be found in Portugal as part of the Treger-Saint Silvestre Collection in São João da Madeira.

Exhibitions featuring Moser's art include: Soit 10 ans - Etats intérieurs, Gallery Christian Berst Art Brut, Paris, 2015; Art Brut/Bruno Decharme/collection abcd, La Maison Rouge, Paris, 2015; Le mur, oeuvres de la Collection Antoine de Galbert, La Maison Rouge, Paris, 2014; Outsider Art Fair, New York, 2014; Big Moser view, Gallery Christian Berst Art Brut, Paris, 2013; Outsider Art Fair, Paris, 2013; Albert Moser, Panorama, University of Kentucky, Lexington, KY, 2011. 


\section{Acknowledgements}

None.

\section{Financial Support}

This research received no specific grant from any funding agency, commercial or not-for-profit sectors.

\section{Conflict of Interest}

None.

\section{References}

Duchamp M (2005). Scritti. Abscondita: Milano.

Foster-Rice G, Rohrbach J (2013). Reframing the New Topographics. Columbia College Chicago Press: Chicago. Jenkins W (1975). New Topographics: Photographs of a Man-Altered Landscape, Exhibition catalogue. International Museum of Photography at the George Eastman House: Rochester, New York.

March Jones P, Rouillé A, Caujolle C (2012). Albert Moser, life as a panoramic, Exhibition catalogue, 1 June - 21 July 2012. Galerie Christian Berst Art Brut, La manufacture de l'image: Paris. 